
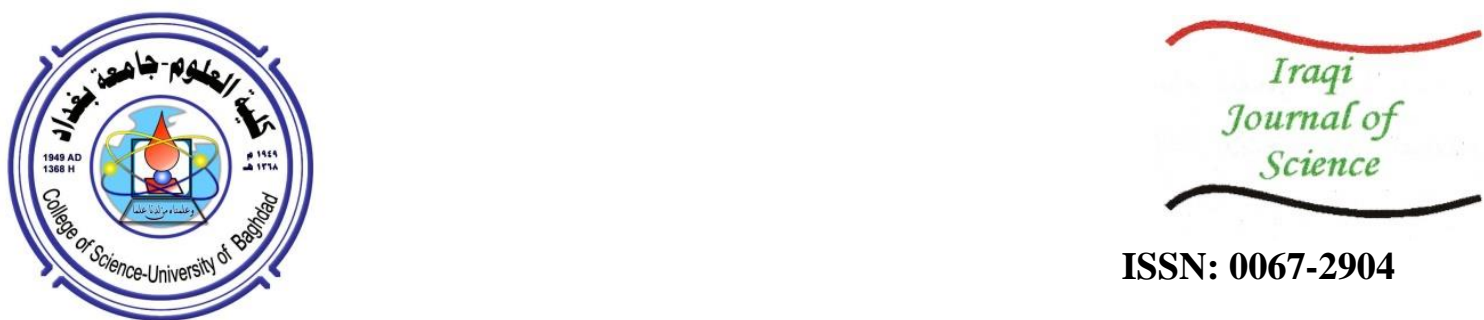

ISSN: 0067-2904

\title{
Studying the Physicochemical Properties and Isolation of Unsaturated Fatty Acids from Edible Oils by GC-MS and Argentated Silica Gel Chromatography
}

\author{
Salim Najmaldain Saber ${ }^{* 1}$, Hikmat Ali Mohamad ${ }^{1}$, Madzlan Aziz ${ }^{2}$ \\ ${ }^{1}$ Department of Chemistry, College of Education, University of Salahaddin. Erbil, Iraq \\ ${ }^{2}$ Department of Chemistry, Faculty of Science, University Technology Malaysia UTM, Johor Bahru, Malaysia
}

Received: 2/4/2020

Accepted: $28 / 5 / 2020$

\begin{abstract}
The core objective of this study was to investigate the physicochemical characteristics and fatty acid composition of the oils of sunflower, olive, virgin coconut and ginger oils, as well as the separation of their unsaturated fatty acids. The data indicated a significant variation in physicochemical properties (acid, saponification, ester, and iodine values) among oils. Transesterification process was carried out at a molar ratio of 1:7:0.1 of oil: methanol: KOH. Fatty acid methyl esters of oils were analyzed by infrared (IR) and gas chromatography-mass (GCMS) spectrometry. Twelve fatty acids were identified, where the major fatty acid of olive oil was found to be oleic acid (89\%), whereas those of sunflower and ginger oils were linoleic acid $(80.9 \%)$ and $(79.3 \%)$, respectively. Sunflower and olive oils were fractionated by $25 \%$ silver nitrate-impregnated silica gel column chromatography. By this method, linoleic acid methyl ester from sunflower and oleic acid methyl ester from olive oil were isolated with high purity percentages and yields. This study is significant for the development of food and pharmaceutical products.
\end{abstract}

Keywords: Physicochemical properties, Fatty Acid composition, Gas chromatography-mass spectrometry and argentated chromatography.

\section{INTRODUCTION}

The characterization of vegetable oils is significant for understanding the mechanism of oil's function in human nutrition and health. The sunflower oil and olive oil are obtained from the seed of the sunflower flower and the fruit of the olive tree, respectively. Both oils contain different fatty acid composition and most of the fatty acids are unsaturated fatty acids, such as linoleic acid and oleic acid [1]. Linoleic acid is one of the most significant polyunsaturated fatty acids (PUFAs) and would reduce plasma cholesterol and triglyceride levels. By several mechanisms, such as the decrease in platelet aggregation and stabilization of atherosclerotic plaque, linoleic acid protects the human body against cardiovascular disease (CVD) [2]. Oleic acid is one example of monounsaturated fatty acids (MUFAs) that are able to prevent coronary heart disease (CHD) and increase the availability of antioxidants [3]. Based on differences in physicochemical properties, there are several technologies available to determine and purify individual MUFAs and PUFAs. Gas chromatography-mass spectrometry (GCMS) is the main technique to determine fatty acids in a variety of samples [4], such as salmon oil [5], milk products [6], nigella sativa oil [7], and sesame oil [8]. Common methods to obtain fractions rich in unsaturated fatty acids include molecular distillation, liquid chromatography, and argentated silica

*Email: salim.saber@su.ed.krd 
gel chromatography. Argentated silica gel column chromatography is an easy, simple, and time saving method to purify unsaturated fatty acids based on the number of double bonds. In this method, the stationary phase is the argentated silica gel and differential elution is carried out to isolate unsaturated fatty acid methyl ester [9]. The MUFAs and PUFAs are currently in demand in pure forms in food nutrition and are being studied to understand their potential roles in human health. In the present work, determination of the physicochemical properties and fatty acid composition of sunflower, olive, virgin coconut and ginger oils, and isolation of MUFAs and PUFAs from olive and sunflower oils by argenatated silica gel column chromatography were conducted.

\section{Materials and Methods}

Olive and ginger oils were purchased from the local market in Kurdistan- Erbil/Iraq, while sunflower and virgin coconut oil (VCO) were purchased from the local market in Malaysia-Johor Bahru. The standards of methyl linoleate (18:2), methyl oleate (18:1), and methyl stearate (18:0) were purchased from Sigma Aldrich-USA. All other chemicals were obtained from the store at the University Technology Malaysia (UTM).

\subsection{Determination of the Physicochemical Properties of the Oil}

Physicochemical properties such as acid value, saponification number, iodinevalue (I.V), and ester value were determined by using standard methods as outlined in the Association of Analytical Communities (A.O.A.C.) [10].

\subsubsection{Acid Value and Free Fatty Acid Content}

Approximately $1 \mathrm{~g}$ of oil sample (sunflower oil, olive oil, virgin coconut oil, or ginger oil) was placed in dried conical flask, then $10 \mathrm{ml}$ absolute ethanol with 2-3 drops of phenolphthalein $(\mathrm{Ph} . \mathrm{Ph})$ were added. The mixture was heated in water bath for $10 \mathrm{~min}$. and, after cooling, it was titrated against $\mathrm{KOH}(0.1 \mathrm{~N})$ until $\mathrm{Ph} . \mathrm{Ph}$ color (pink color) appeared. The acid value and free fatty acid content were calculated as in the equations below.

$A V=\frac{m \boldsymbol{L} \text { of } \mathrm{KOH} \times \boldsymbol{N} \times \mathbf{5 6}}{\text { Weight of } \boldsymbol{s a m p l}}=m g$ of $\mathrm{KOH}$ Equation 1

Where AV: acid value, $\mathrm{N}$ : Normality of $\mathrm{KOH}=0.1$

\% Free Fatty Acid $($ FFA $)=A V \times 0.503$ Equation 2

\subsubsection{Saponification Number}

Approximately $2 \mathrm{~g}$ of oil sample (sunflower oil, olive oil, virgin coconut oil, or ginger oil) was placed in dried conical flask, then $25 \mathrm{ml}$ of alcoholic potassium hydroxide solution $(0.5 \mathrm{~N})$ was added. The mixture was heated with reflux condenser in boiling water bath for $1 \mathrm{~h}$. While the solution still hot, 3 drops of $\mathrm{Ph} . \mathrm{Ph}$ indicator were added and the mixture was titrated against $0.5 \mathrm{~N}$ hydrochloric acid. The same procedure was also repeated but without sample. Saponification value was calculated as in the following equations.

$$
S P \text { number }=\frac{56.1 \times(B-S) \times N \text { of } \mathrm{HCl}}{\text { weight of sample }(\mathrm{g})} \quad \text { Equation } 3
$$

Where SP: Saponification Value, N: Normality of $\mathrm{HCl}=0.5 \mathrm{~N}$, B: volume of $\mathrm{HCl}$ required for blank, $\mathrm{S}$ : volume of $\mathrm{HCl}$ required for sample

\subsubsection{Ester value (EV)}

The ester value is defined as the $\mathrm{mg}$ of $\mathrm{KOH}$ required to react with glycerol after saponifiying one gram of the oil. It is calculated by saponification value (SV) and the acid value (AV), as described by the equation:

\section{Ester value $(E V)=$ saponification value $(S V)-$ acid value $(A V) \quad$ Equation 4 \%glycerol $=$ Ester value $\times 0.054664$ Equation 5}

\subsubsection{Iodine Value (I.V)}

Approximately $0.25 \mathrm{~g}$ of oil sample (sunflower oil, olive oil, virgin coconut oil, or ginger oil) was placed in dried conical flask then $10 \mathrm{ml}$ of chloroform was added. To this mixture, $30 \mathrm{ml}$ of Hanus solution (prepared by dissolving $18.2 \mathrm{~g}$ of iodine in $1 \mathrm{~L}$ of glacial acetic acid and then adding $3 \mathrm{ml}$ of bromine water for increasing the halogen content) was added and the flask was closed completely by parafilm. The solution was left for $30 \mathrm{~min}$ with shaking continuously. After that, $10 \mathrm{ml}$ of $15 \%$ potassium iodide solution and $100 \mathrm{ml}$ of distilled water were added. The iodine solution was titrated against sodium thiosulfate solution $(0.1 \mathrm{~N})$ and starch solution was used as indicator. Titration was continued until the blue color disappeared (the volume in $\mathrm{ml}$ of $\mathrm{Na}_{2} \mathrm{~S}_{2} \mathrm{O}_{3}$ at the end point represents $\mathrm{S}$ 
in equation 6). The same procedure was repeated but without sample (the volume in ml of $\mathrm{Na}_{2} \mathrm{~S}_{2} \mathrm{O}_{3}$ at the end point represents $B$ in equation 6 ). The iodine number calculated by the following equation:

Iodine Value $=\frac{(B-S) \times N \times 0.127 \frac{\mathrm{g}}{\mathrm{meq}} \times 100}{\text { weight of sample }(g)} \quad$ Equation 6

Where B: Volume of $\mathrm{Na}_{2} \mathrm{~S}_{2} \mathrm{O}_{3}$ for blank, $\mathrm{S}$ : Volume of $\mathrm{Na}_{2} \mathrm{~S}_{2} \mathrm{O}_{3}$ for Sample, N: normality of $\mathrm{Na}_{2} \mathrm{~S}_{2} \mathrm{O}_{3}$.

\subsection{Transesterification of Oils}

For transesterification reaction, 1:7:0.1 molar ratio of oil, methanol and sodium hydroxide was used. The calculated amount of oil sample (sunflower oil, olive oil, virgin coconut oil, ginger oil) was transferred into flask, and oil was preheated at the required temperature before starting the reaction. The calculated amount of sodium hydroxide $(2.2 \mathrm{~g})$ in $100 \mathrm{ml}$ methanol was stirred until the sodium hydroxide completely dissolved in methanol. The prepared methanol catalyst solution ( $28 \mathrm{ml}$ of $2.2 \%$ $\mathrm{CH} 3 \mathrm{ONa}$ ) was poured into the pre-heated oil, and the reaction mixture was heated under reflex for 90 $\min$ at $45^{\circ} \mathrm{C}$ with constant stirring. Following the transesterification, the reaction mixture was left to cool down. The mixture was separated into two phases after cooling. The upper phase consisted of methyl esters and the lower phase contained glycerol, the excess methanol, and the un-reacted catalyst. After separation of both layers by separation funnel, fatty acid methyl ester (FAME) layer was washed with $400 \mathrm{ml}$ distilled water $(50 * 8)$. The FAMEs were tested by TLC and FTIR. Finally, the FAMEs content were determined by preparing the sample for GC-FID and GC-MS.

\subsection{Total FAMEs separation on thin layer chromatography (TLC)}

Briefly, $100 \mu \mathrm{L}$ of each sample (oils, FAMEs, and free fatty acid) was carefully loaded onto a silica gel plate (Analtech, uniplate, $10 \times 10 \mathrm{~cm}$ ) and the plate was developed in a solution consisting of hexane/diethyl ether/acetic acid (94/4/2 v/v/v) [11]. The spot was visualized by UV-light.

\subsection{Gas chromatography-Mass spectrometry}

The fatty acid composition of each type of oil was estimated by gas chromatography-Flameionization detection (GC-FID) and GC-MS. The GC- instrument conditions were: column: Elite 5 MS with dimensions of $30.0 \mathrm{~m} \times 250 \mu \mathrm{m}$; oven temperature: initially held at $140{ }^{\circ} \mathrm{C}$ for $5 \mathrm{~min}$, increased to $240{ }^{\circ} \mathrm{C}$ at $4{ }^{\circ} \mathrm{C} / \mathrm{min}$, and then held for $5 \mathrm{~min}$; injector, transfer and source temperatures: $250{ }^{\circ} \mathrm{C}, 200{ }^{\circ} \mathrm{C}$ and $150{ }^{\circ} \mathrm{C}$, respectively; carrier gas: helium; and total scan time is $50 \mathrm{~min}$. The individual peaks of the gas chromatogram were analyzed by NIST, NBS and Wiley GC-MS library and the relative percentage of fatty acid esters was calculated from total ion chromatography by computerized integrator [12]

\subsection{Separation of Fatty acid methyl ester by Argentation Chromatography \\ 2.5.1. Preparation of silver impregnated silica}

Sliver nitrate solution $\left(\mathrm{AgNO}_{3}, 15 \mathrm{~g}\right)$ was prepared by dissolving $15 \mathrm{~g}$ of $\mathrm{AgNO}_{3}$ in $60 \mathrm{~mL}$ ethanol. Silica gel (0.06-0.2 mm, 70-230 mesh ASTM; mean pore diameter of $6 \mathrm{~nm}$, specific surface area of $500 \mathrm{~m} 2 / \mathrm{g}$ ) in $100 \mathrm{ml}$ ethanol (95\%) was added to the sliver nitrate solution under stirring for $2 \mathrm{~h}$. Then, the ethanol was evaporated by rotary evaporator at $60^{\circ} \mathrm{C}$ and the residual (silver impregnated silica) was activated by heating overnight $\left(110 \pm 2^{\circ} \mathrm{C}\right)$ in hot air oven to prepare $\mathrm{Ag}$-silica powder. $\mathrm{Ag}$ silica powder was cooled and kept in the dark desiccator for further use.

\subsubsection{Argentation chromatography of Ag-silica}

The water-jacketed column (45 cm $50 \mathrm{~mm}$ i.d.) was half-filled with n-hexane and Ag-silica ( $5 \mathrm{~g}$ ) in n-hexane $(5 \mathrm{ml})$ was poured into the column. Fatty acid methyl esters fraction obtained after transesterification of oils $(5 \mathrm{~g})$ in n-hexane was applied on the chromatography column. The fatty acid methyl esters fraction was eluted with three different organic solvents, first $100 \% \mathrm{n}$-hexane, second $2 \%$ acetone:n-hexane, third 5\% acetone:n-hexane. The fractions were collected in fraction tubes (5 $\mathrm{mL}$ per tube), then each fraction was tested by TLC $(5 \mathrm{~cm} 20 \mathrm{~cm})$. The fractions which contain fatty acid methyl ester were mixed and concentrated. The purity of the concentrated methyl esters was validated using GC-FID and GC-MS.

\section{Results and discussion}

\subsection{Physicochemical Properties of the Oil}

\subsubsection{Acid value}

The quality of oil may be measured by acid value and free fatty acids content. Acid value is the value related to the free fatty acid in the oil. This value must not be high, since high acid value causes discoloration of oil. The low acid value indicates that it is suitable for use. The value was determined by titration method between free fatty acids and $\mathrm{KOH}$. The acid values of the oils are shown in table 
(1). The results show that the olive oil has highest acid value $(0.50 \mathrm{mgKOH} / \mathrm{g}$ oil $)$, which indicated that this oil contains high concentrations of free fatty acids, while the lowest acid value was recorded in ginger oil (0.0.37 mg KOH/g oil). According to the Food and Agriculture Organization (FAO) and World Health Organization (WHO), the recommended acid value should be below $0.6 \mathrm{mgKOH} / \mathrm{g}$ of oil. The acid values of all analyzed oils were below the permissible limit. The United States Department of Agriculture and some European countries have reported that the maximum FFA levels of oil should range from $1.0 \%$ to $2.5 \%$ [13]. In this study, the maximum level of FFA acid is $0.25 \%$, which confirms the results of Sebastian et al. [14] who noted that the high acid value causes rancidity of oil.

\subsubsection{Saponification value}

Saponification is the process of breaking down triglyceride to fatty acids and glycerol. Also it is useful to know the difference between the chain lengths of the fatty acids and the triglycerides. Saponification value is inversely proportional to the molecular weight. Small saponification value indicates that the oil has long chain fatty acids with large molecular weight. The saponification value of the sunflower, olive, ginger and virgin coconut oil were 191.58, 208.72, 164, 61 and $145.70 \mathrm{mg}$ $\mathrm{KOH} / \mathrm{g}$, respectively (Table-1). These values are within the range of edible oils and may be suitable for soap production. The values also indicated that the fatty acids from virgin coconut oil are low chain. According the FAO and WHO [15], the recommended saponification values of sunflower, olive and virgin coconut oil are 188-1974, 182-194 and 248-265 mg KOH/g oil, respectively. Saponification values of the sunflower and olive oils found in the present study agreed with FAO/WHO recommended values, but that for virgin coconut oil was below the limits, whereas the value for ginger oil is not recorded at FAO/WHO recommended values [15].

\subsubsection{Ester Value (EV)}

The ester value is calculated by subtracting the acid value from the saponification value of the corresponding oils. The ester value of all oils were calculated by the equation 4 . The result of ester value of all oils are shown in the Table-1.

\subsubsection{Iodine Value (IV)}

Iodine value is the property of oil that is used for measuring the degree of unsaturation. Iodine value is directly proportional to the number of carbon double bonds in fatty acid. High iodine value indicates that the oil has a high content of unsaturated fatty acids. Iodine values of oils are shown in Table-1. Sunflower oil showed the highest iodine value, whereas virgin coconut oil had the lowest. The results show that the sunflower, ginger and olive oils are rich with unsaturated fatty acids. According to the iodine value, most of fatty acids in virgin coconut oil are saturated . According to FAO/WHO [15], the iodine value of sunflower and olive oils should be between $118-141$. Based on these results, the iodine value of both oils are within the recommended range. On the other hand, the iodine value of virgin coconut oil is high than the recommended value, whereas of the value for ginger oil is not recorded in the literatures.

Table 1-Summary of results of analysis for quality parameters and physicochemical Properties of the Sunflower, Olive, Virgin coconut and Ginger Oils

\begin{tabular}{|c|c|c|c|c|c|c|}
\hline Oils & $\begin{array}{c}\text { S.V } \\
\mathrm{mg} \mathrm{KOH} / \mathrm{g} \text { oil }\end{array}$ & $\begin{array}{c}\mathrm{AV} \\
\mathrm{mg} \mathrm{KOH} / \mathrm{g} \text { oil }\end{array}$ & EV & \% Glycerol & I.V & $\%$ FFA \\
\hline Sunflower & 191.58 & 0.45 & 191.13 & 10.44 & 136.4 & 0.22 \\
\hline Olive & 194.8 & 0.50 & 194.3 & 10.62 & 88.15 & 0.25 \\
\hline $\begin{array}{c}\text { virgin } \\
\text { coconut oil }\end{array}$ & 214.79 & 0.41 & 214.38 & 11.71 & 12.60 & 0.20 \\
\hline Ginger & 164.61 & 0.37 & 164.24 & 8.97 & 78.43 & 0.18 \\
\hline
\end{tabular}

S.V: Saponification values, AV: Acid Value, EV: Ester Value, I.V: Iodine Value, FFA: Free Fatty Acid

\subsection{Transesterification Reaction}

The total yield of FAMEs is dependent on four parameters, which are molar ratio of methanol to oil, amount of catalyst, reaction time, and temperature. To obtain maximum conversion, the following reaction conditions were used: molar ratio of oil: methanol: $\mathrm{KOH}$ equal to 1:7:0.1, temperature of $45^{\circ} \mathrm{C}$ for $90 \mathrm{~min}$. The total yield of FAME is shown in Table-2. Agnew et al. [16] reported that the 
reaction time and temperature are important factors and can impact FAME yield.

Table 2 Transesterification conditions with \% yield of the Sunflower, Olive, Virgin coconut and Ginger Oils

\begin{tabular}{|l|l|l|l|}
\hline Oil & Time $(\min )$ & Temp. ${ }^{\circ} \mathrm{C}$ & Yield \% \\
\hline Sunflower & 90 & 45 & 94 \\
\hline Olive & 90 & 45 & 97 \\
\hline virgin coconut oil & 90 & 45 & 92 \\
\hline Ginger & 90 & 45 & 86 \\
\hline
\end{tabular}

Note: Molar ratio of oil: methanol: KOH (1:7:01)

3.3. Results of TLC Measurements

The final product of transesterification reaction was loaded into TLC plate and compared with standard FAME, free fatty acid, and oil (Figure-1). TLC results showed that the oil was successfully converted to FAME, because the retention factor $\left(\mathrm{R}_{\mathrm{f}}\right)$ values of FAME, oil, and Free fatty acids were different. The Rf values of all compounds are illustrated in Table-3. The table shows that the prepared and standard FAMEs have the same $\mathrm{R}_{\mathrm{f}}$. The best solvent mixture for separating FAMEs was that made of hexane: diethyl ether: acetic acid (94:4:2 v: v: v).

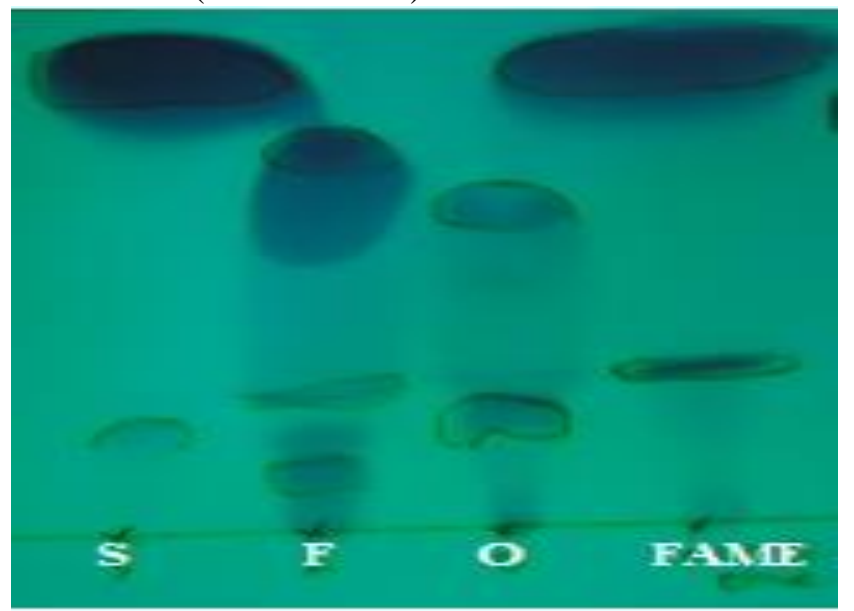

Figure 1-TLC silica-gel plate of FAME developed by a mixture of solvent (hexane: diethyl ether: acetic acid) (94:4:2 v:v:v). S: linoleate standard, F: linolic acid, O: olive oil, and FAME: prepared FAME of olive oil.

Table 3 Retention factor $\left(\mathrm{R}_{\mathrm{f}}\right.$.) of oils and FAMEs

\begin{tabular}{|l|l|l|l|l|}
\hline & Sunflower & Olive & $\begin{array}{l}\text { virgin } \\
\text { coconut } \\
\text { oil }\end{array}$ & Ginger \\
\hline Solvent & 1 & 1 & 1 & 1 \\
\hline linoleate standard & 0.88 & 0.87 & 0.90 & 0.88 \\
\hline linoleic acid & 0.71 & 0.72 & 0.70 & 0.73 \\
\hline oil & 0.67 & 0.62 & 0.66 & 0.55 \\
\hline FAME & 0.88 & 0.87 & 0.90 & 0.88 \\
\hline
\end{tabular}

\subsection{Infrared Spectra}

To visualize the conversion of oil to FAME, FT-IR spectroscopy was used. IR-spectra of all oils and FAMEs are shown in Table-4. After analysis of spectra of oils and FAMEs, the results show the significant difference between these two molecules. In IR spectra, $\mathrm{C}=\mathrm{O}$ strong absorption bands of oils were found at $1745-1746 \mathrm{~cm}^{-1}$, but $\mathrm{C}=\mathrm{O}$ stretching of FAME was found at $1742-1743 \mathrm{~cm}^{-1}$. The both groups regarded to $\mathrm{C}=\mathrm{O}$ in the ester. The most important region to detect differences between oil and FAME was that at $900-1400 \mathrm{~cm}^{-1}$. The $\mathrm{C}-\mathrm{H}$ in the $\mathrm{CH}_{2}-\mathrm{O}$ group which is present in oil was found at $1376-1377 \mathrm{~cm}^{-1}$, while these peaks are not found in FAMEs. However, a new signal in FAMEs could be observed at $1435-1437 \mathrm{~cm}^{-1}$, which is attributed to $\mathrm{C}-\mathrm{H}$ in $\mathrm{O}-\mathrm{CH}_{3}$, whereas these 
peaks are not found in oil. The signals for symmetric and asymmetric $\mathrm{C}-\mathrm{H}$ stretching vibrations of methyl and methylene groups, respectively, were found in $2960-2850 \mathrm{~cm}^{-1}$. The absorbance at $3008 \mathrm{~cm}^{-1}$ shows $\mathrm{C}-\mathrm{H}$ in $\mathrm{C}=\mathrm{C}-\mathrm{H}$ stretching frequency, while this peak is not found in virgin coconut oil because most fatty acids in virgin coconut oil are saturated. Such observations are also reported in the literature [17]. The absorbance at $722-723 \mathrm{~cm}^{-1}$ shows $-\mathrm{CH}_{2}$ rocking and this peak is found in both oil and FAMEs, as supported by literature [18]. Other differences between oils and FAMEs are explained in Table-4 and Figure-2.

Table 4 Characteristic IR absorption bands for oils and FAMEs of oils

\begin{tabular}{|c|c|c|c|c|c|c|c|c|}
\hline S.O & S.M & O.O & O.M & V.O & V.M & G.O & G.M & Assignment \\
\hline 3007 & 3008 & 3009 & 3009 & - & - & 3009 & 3009 & $\begin{array}{c}v(\mathrm{C}-\mathrm{H}) \text { in } \\
\mathrm{C}=\mathrm{C}-\mathrm{H}\end{array}$ \\
\hline Overlapped & 2925 & Overlapped & 2925 & Overlapped & 2926 & 2926 & 2926 & $v(\mathrm{C}-\mathrm{H})$ \\
\hline 2855 sh. & 2854 & 2854 sh. & 2854 & 2856 sh. & 2855 & 2854 & 2855 & $v(\mathrm{C}-\mathrm{H})$ \\
\hline 1745 & 1743 & 1746 & 1743 & 1745 & 1743 & 1746 & 1743 & $v(\mathrm{C}=\mathrm{O})$ \\
\hline 1654 & 1654 & 1652 & 1650 & - & - & 1654 & 1654 & $v(\mathrm{C}=\mathrm{C})$ \\
\hline 1464 & 1463 & 1464 & 1463 & 1465 & 1465 & 1464 & 1464 & $\begin{array}{c}\delta(\mathrm{C}-\mathrm{H}) \text { in } \\
\text { methyl }\end{array}$ \\
\hline- & 1435 & - & 1435 & - & 1436 & - & 1436 & $\begin{array}{c}\mathrm{C}-\mathrm{H} \text { in } \\
(\mathrm{CO})-\mathrm{O}-\mathrm{CH}_{3}\end{array}$ \\
\hline 1377 & - & 1377 & -- & 1377 & 1376 & 1377 & 1376 & $\begin{array}{c}\mathrm{C}-\mathrm{H} \text { in O- } \\
\mathrm{CH}\end{array}$ \\
\hline- & 1171 & - & 1171 & - & 1170 & - & 1171 & $\begin{array}{c}\mathrm{C}-\mathrm{H} \text { in O- } \\
\mathrm{CH}\end{array}$ \\
\hline 967 & - & 967 & -- & 963 & - & 967 & - & $\begin{array}{c}-\mathrm{CH} 2 \text { in } \\
\text { RCOCO- }\end{array}$ \\
\hline
\end{tabular}

sh: band occurs as shoulder, - no absorption band occurs. S.O: sunflower oil, SM: FAME of sunflower oil, O.O: Olive oil, OM: FAME of Olive oil, V.O: virgin coconut oil, VM: FAME of virgin coconut oil, G.O: ginger oil, GM; FAME of ginger oil.

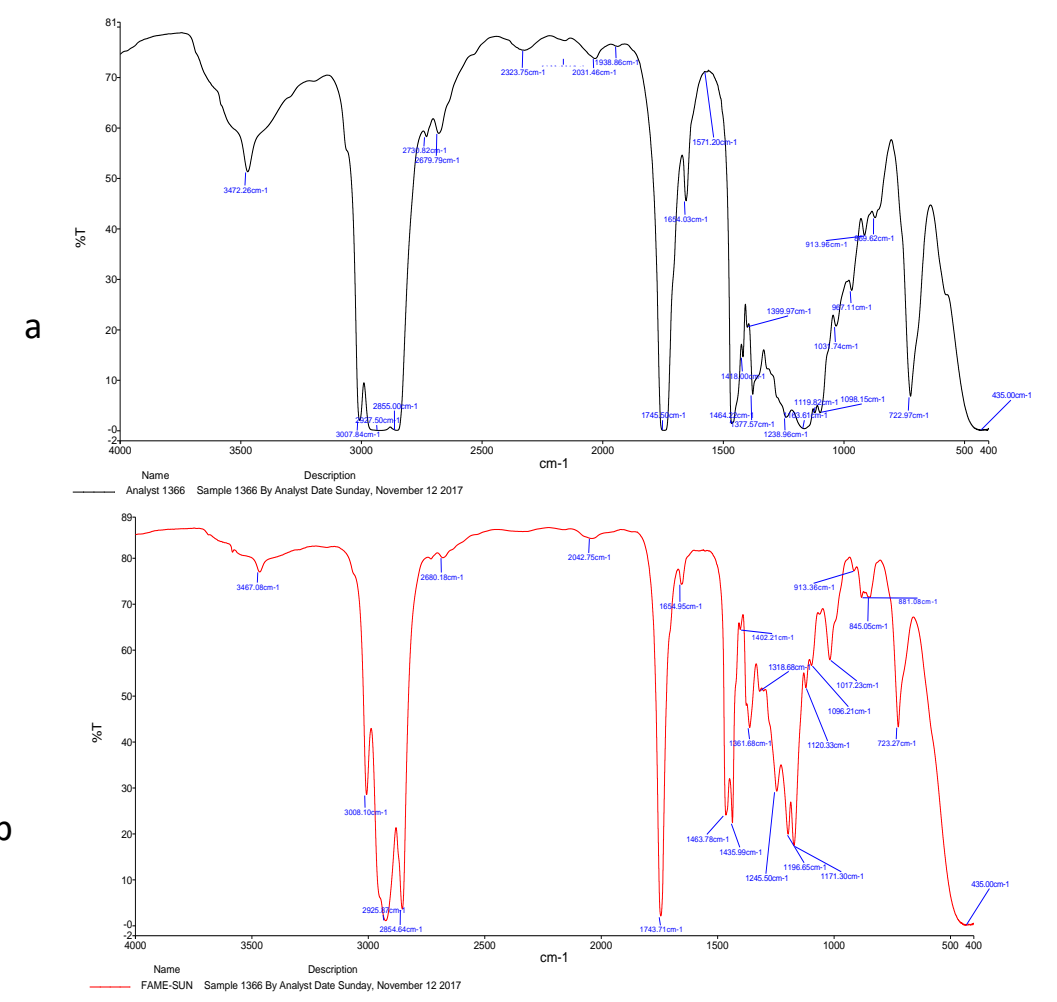

Figure 2 FT-IR spectra of a. Sunflower oil, b. FAME of sunflower Oil. 


\subsection{Fatty acid composition}

The GC-MS analysis was used to determine fatty acid profile of oils. In GC, the individual peaks were analysed, while the MS database was used to identify fatty acids. The relative percentages of fatty acids, which are shown in Table-5, were calculated according to total ion chromatography and computerized integrator. The fatty acid compositions of sunflower oil, olive oil, virgin coconut oil, and ginger oil are shown in Figures-(3 and 4). Twelve fatty acids were determined as FAMEs and their compositions were evaluated for each different sample.

According to Table-5, oleic acid is the main MUFA. Olive oil contained the highest percentage of oleic acid (89\%) while virgin coconut oil contained 7.6\%. Kotha et al. [19] showed that the higher concentration of oleic acid in oils can decrease low-density lipoprotein (LDL)-cholesterol without decreasing the high-density lipoproteins (HDL) cholesterol.

As shown in Table-5, linoleic acid is the most significant type PUFA. Sunflower oil contained the highest percentage of linoleic acid $(80.9 \%$ ) while ginger oil contained $79.3 \%$. Linoleic acid has many biological activities, such as the prevention of distinct heart vascular diseases [20].

Dodecanoic acid and tetradecanoic acid are the most important saturated fatty acids (SFAs). The virgin coconut oil contained the highest percentage of dodecanoic acid $(46.2 \%)$ and tetradecanoic acid $(18.6 \%)$, while the percentage of dodecanoic acid was $0.12 \%$ in ginger oil.

Palmitic acid and stearic acid, which are saturated fatty acids, are found in all types of oils but with different ratios in the present study. The ratios of palmitic acid and stearic acid were between 5.3 12.3 , \% and $2.8-5.3 \%$, respectively. Octanoic acid (7.1\%) and tetradecanoic acid (18.6\%) were only found in virgin coconut oil, whereas 12 -hydroxy-oleic acid $(2.8 \%)$ was only found in ginger oil. The results in Table- 5 demonstrate that olive and ginger oils contain high percentage of oleic acid and linoleic acid, respectively[21].

Table 5 Fatty acid compositions of oils

\begin{tabular}{|c|c|c|c|c|c|}
\hline Fatty Acids (\%) & Carbon number & Sunflower & Olive & $\begin{array}{c}\text { virgin } \\
\text { coconut } \\
\text { oil } \\
\end{array}$ & Ginger \\
\hline Octaic acid & C8:0 & ------- & ------- & 7.1 & ------- \\
\hline Decanoic & C10:0 & ------ & ------ & 6.4 & 0.11 \\
\hline Dodecanoic & $\mathrm{C} 12: 0$ & ------ & ------ & 46.2 & 0.12 \\
\hline Tetradecanoic acid & $\mathrm{C} 14: 0$ & ------ & ------ & 18.6 & ----- \\
\hline Palmitic acid & C16:0 & 11.8 & 5.13 & 9.3 & 12.3 \\
\hline Linoleic acid & C18:n9,12 & 80.99 & ----- & ----- & 79.3 \\
\hline Oleic acid & C18:n9 & ------ & 89 & 7.6 & ----- \\
\hline Oleic acid-12hydroxy & $\mathrm{C} 18: \mathrm{n} 9,12 \mathrm{OH}$ & ------ & ----- & 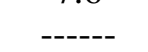 & 2.8 \\
\hline Stearic acid & C18:0 & 5.03 & 2.8 & 3.3 & 4.12 \\
\hline Cis-13-Eicosenoic acid & $\mathrm{C} 21: \ln 13$ & 0.38 & 1.3 & ------ & ------ \\
\hline Eicosenoic acid & C20:0 & 0.47 & 0.6 & ------ & 0.44 \\
\hline Docosanoic acid & $\mathrm{C} 22: 0$ & 0.49 & 0.4 & ------ & 0.39 \\
\hline \multicolumn{2}{|c|}{ Total saturated FA (TSFA) } & 17.79 & 8.93 & 90.9 & 17.48 \\
\hline \multicolumn{2}{|c|}{ Total Unsaturated FA (TUFA) } & 81.37 & 90.3 & 7.6 & 82.1 \\
\hline \multicolumn{2}{|c|}{ St. / Unst. (TSFA/TUFA) } & 0.218 & 0.099 & 11.96 & 0.21 \\
\hline
\end{tabular}




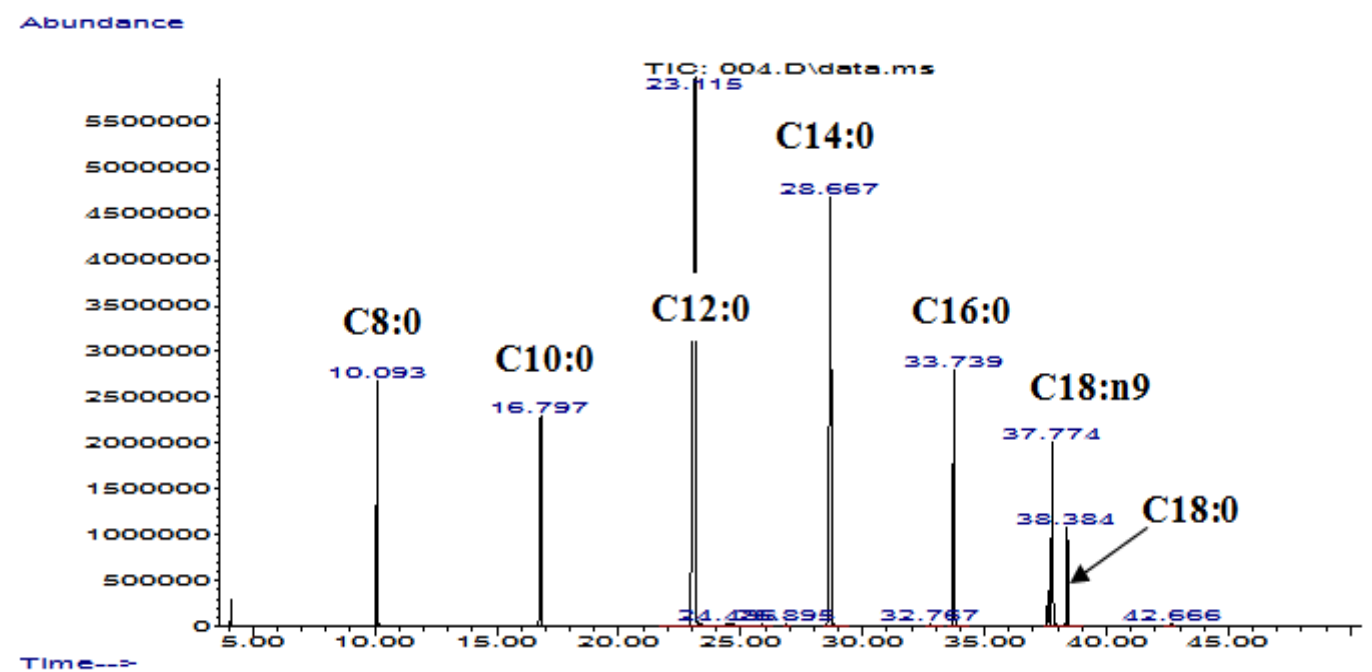

Figure 2-GC-FID chromatogram of FAME of virgin coconut oil

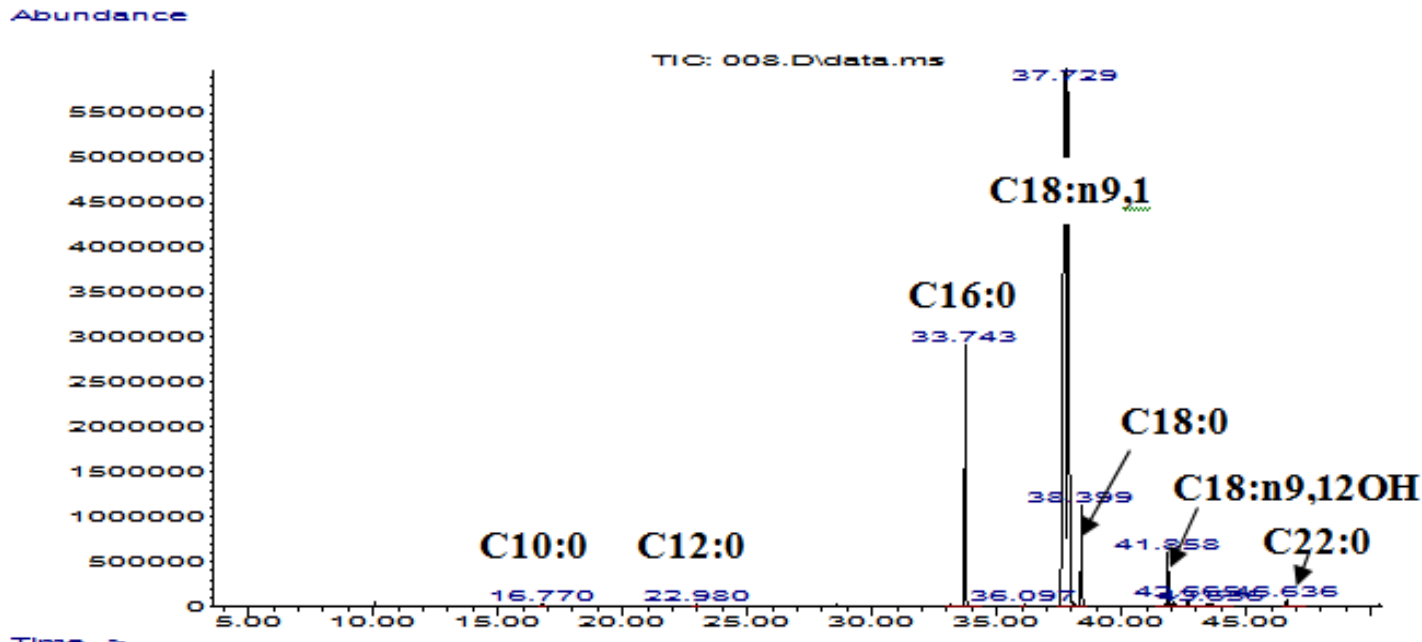

Figure 3-GC-FID chromatogram of FAME of ginger oil.

The molecular ion and base peaks of FAMEs were obtained from Mass spectra and the values for all fatty acids are shown in Table- 6 and Figures- 5 and 6 . Table- 6 shows that the base peak $(100 \%)$ of all saturated fatty acids is $\mathrm{m} / \mathrm{z}=74$, and that this base peak is related to $\mathrm{CH}_{3} \mathrm{O}-\mathrm{C}(=\mathrm{OH}+)-\mathrm{CH}_{2}$ fragment, which represents McLafferty rearrangement. However, the base peak of PUFAs and MUFAs are $\mathrm{m} / \mathrm{z}=67$ and 55 , respectively, where the former is related to $\left[\mathrm{CH}_{2}=\mathrm{CHCH}=\mathrm{CH}-\mathrm{CH}_{2}\right]+$ fragment and the latter is related to $\left[\mathrm{CH}_{2}=\mathrm{CHCH} 2 \mathrm{CH}_{2}\right]+$ fragment. In addition, the molecular ion of oleic acid-12hydroxy -methyl ester was not detected, but the molecular ion at $294 \mathrm{~m} / \mathrm{z}$ is the molecular mass of oleic acid-12hydroxy -methyl ester after the loss of one molecular of water. The other significant fragments are 198, 127 and $195 \mathrm{~m} / \mathrm{z}$. Molecular ion and base peak of SFAs, MUFAs and PUFAs have been reported in the literature [22].

Table 6 Molecular ion and base peaks of FAME from olive oil

\begin{tabular}{|c|c|c|c|c|c|c|}
\hline FAME & $\begin{array}{c}\text { Molecular ion } \\
\text { peak (m/z) }\end{array}$ & $\begin{array}{c}\text { Base } \\
\text { peak } \\
(\mathbf{m} / \mathbf{z})\end{array}$ & \multicolumn{3}{|c|}{ Fragments } \\
\hline $\begin{array}{c}\text { Octaic acid -methyl } \\
\text { ester }\end{array}$ & 158 & 74 & $127(\mathrm{M}-31)$ & $115(\mathrm{M}-43)$ & ----- & $101(\mathrm{M}-57)$ \\
\hline Decanoic methyl ester & 186 & 74 & $157(\mathrm{M}-29)$ & $143(\mathrm{M}-43)$ & $129(\mathrm{M}-57)$ & $101(\mathrm{M}-85)$ \\
\hline
\end{tabular}




\begin{tabular}{|c|c|c|c|c|c|c|}
\hline $\begin{array}{c}\text { Dodecanoic -methyl } \\
\text { ester }\end{array}$ & 214 & 74 & $143(\mathrm{M}-71)$ & $171(\mathrm{M}-43)$ & $157(\mathrm{M}-186)$ & $101(\mathrm{M}-113)$ \\
\hline $\begin{array}{c}\text { Tetradecanoic acid } \\
\text { methyl ester }\end{array}$ & 242 & 74.1 & ---- & $199(\mathrm{M}-43)$ & $143(\mathrm{M}-99)$ & $101(\mathrm{M}-141)$ \\
\hline $\begin{array}{c}\text { Palmitic acid -methyl } \\
\text { ester }\end{array}$ & 270 & 74.1 & $239(\mathrm{M}-31)$ & $227(\mathrm{M}-43)$ & $199(\mathrm{M}-71)$ & $143(\mathrm{M}-127)$ \\
\hline $\begin{array}{c}\text { Linoleic acid methyl } \\
\text { ester }\end{array}$ & 294 & 67 & $263(\mathrm{M}-31)$ & $220(\mathrm{M}-74)$ & $178(\mathrm{M}-116)$ & --- \\
\hline $\begin{array}{c}\text { Oleic acid-methyl ester } \\
\begin{array}{c}\text { Oleic acid-12hydroxy } \\
\text { methyl ester }\end{array}\end{array}$ & 296 & 55.1 & $264(\mathrm{M}-32)$ & $222(\mathrm{M}-74)$ & $180(\mathrm{M}-116)$ & $101(\mathrm{M}-113)$ \\
\hline \begin{tabular}{c} 
Stearic acid-methyl ester \\
\hline
\end{tabular} & 298 & 74.1 & $267(\mathrm{M}-31)$ & $255(\mathrm{M}-43)$ & $199(\mathrm{M}-99)$ & $143(\mathrm{M}-155)$ \\
\hline
\end{tabular}

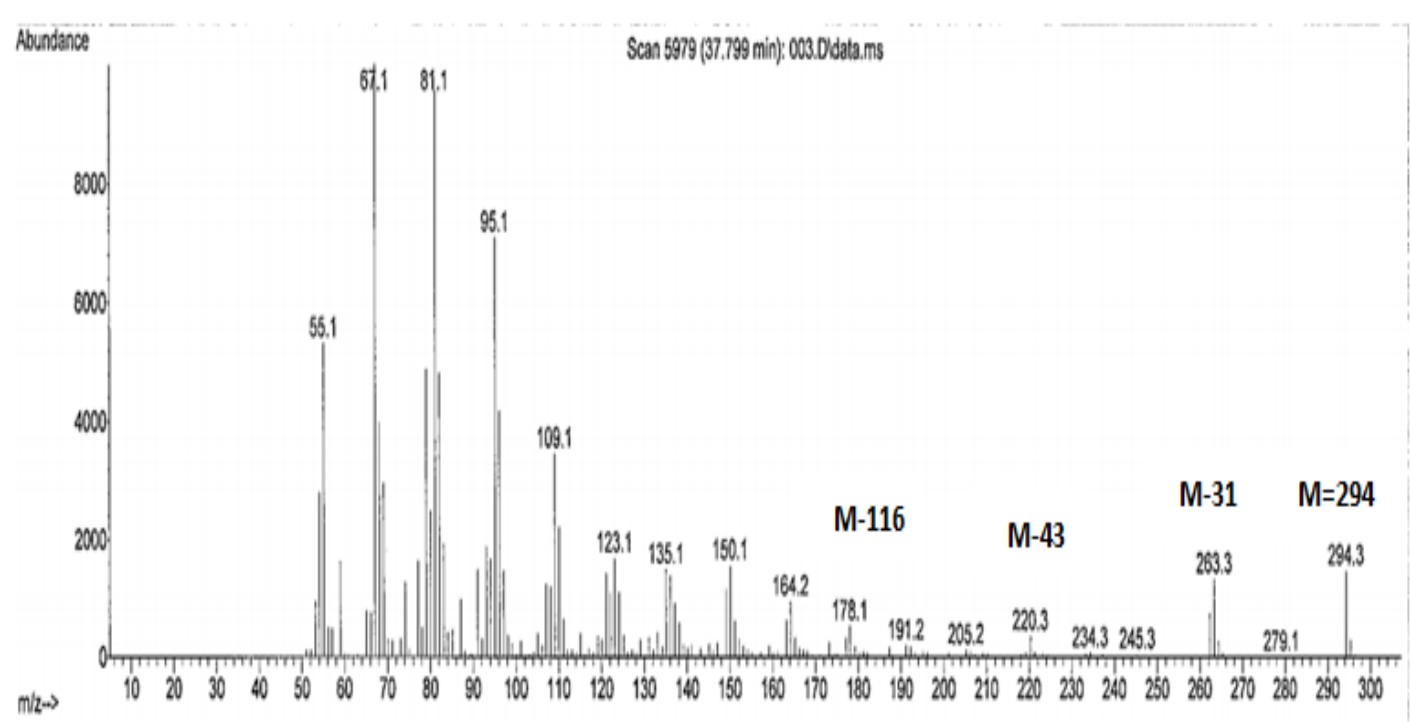

Figure 4-The MS of linoleic acid methyl ester

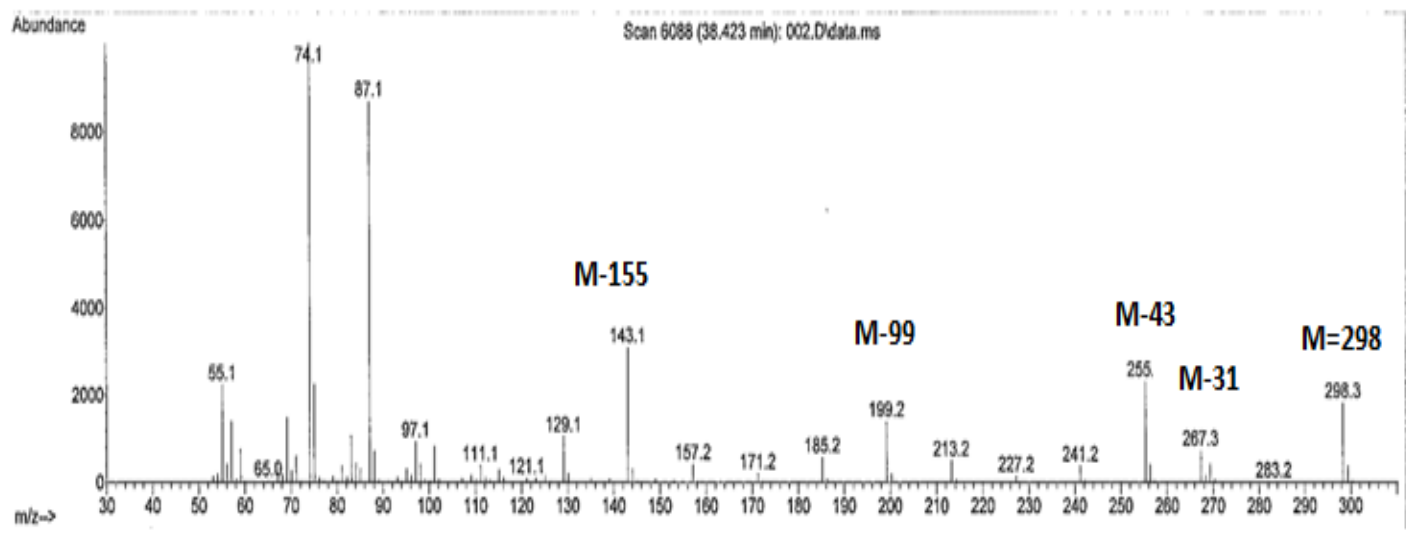

Figure 5 The MS of stearic acid methyl ester.

The molecular weights of each of the FAMEs were calculated by Mass spectra. The average molecular weight of oil can be calculated by the average molecular weight of individual fatty acids and the percentage of individual fatty acids in the oil. Equation (7) can be used to calculate molecular weight of oil. The number 41 is the molecular weight of glycerol without $\mathrm{OH}$ groups. The molecular 
weight values of oils (sunflower 875.02, olive 884.71, virgin coconut oil 678.39 , and ginger 873.9 $\mathrm{g} / \mathrm{mol}$ ) which were found by equation (7), have a good agreement with those reported in the literature [23].

$M . W=\frac{[3 \Sigma(\text { M.W fatty acids } \times \% \text { fatty acids })]}{100}+41$ Equation 7

\subsection{Separation Fatty acid methyl ester by Argentation Chromatography}

In this technique, the FAMEs are separated according to polarity of the fatty acids. The polarity of the FAMEs depends on the number of double bonds contained in each fatty acids. High polar fatty acids have more double bonds. For example, linoleic acid is more polar then oleic acid because of the higher number of double bonds. Ag-Si column chromatography was used for the separation of FAMEs based on the number of double bonds. In this technique, activated silver impregnated silica is used as a stationary phase. When the mixture of the FAMEs (FAMEs of olive and sunflower oils) passes through the column, the silver $\left(\mathrm{Ag}^{+}\right)$ion forms polar complexes with the fatty acids through the double bonds. The FAMEs are selectively eluted by changing the polarity of the eluent solvent mixture. Acetone-hexane mixture was used as an eluent, the polarity of which was increased by increasing acetone content. The ratios of the acetone-hexane in the eluent are shown in the table below:

Table 7-Solvent systems for elution of FAMEs

\begin{tabular}{|c|c|c|c|c|}
\hline & Hexane $(\mathrm{V})$ & Acetone $(\mathrm{V})$ & \% Hexane & \% Acetone \\
\hline A & 100 & 0 & 100 & 0 \\
\hline B & 99 & 1 & 99 & 1 \\
\hline C & 98 & 2 & 98 & 2 \\
\hline D & 95 & 5 & 95 & 5 \\
\hline
\end{tabular}

The results show that the saturated FAMEs eluted with $100 \%$ of hexane and oleic acid (monounsaturated fatty acid) were separated when the polarity of the solvent was increased by $1 \%$ of acetone, while linoleic acid was eluted by more polar eluents (2\% and 5\% acetone). Sunflower FAME profile is suitable for the separation of linoleic acid, while olive oil FAME profile is suitable for the separation of oleic acid, since both sunflower and olive oil contain $80 \%$ of linoleic acid. The fatty acid profiles of each fraction obtained by Ag-Si column chromatography are confirmed by TLC and GCMS.

All column fractions eluted with solvent D were tested by TLC to detect which fractions contain FAME. The TLC results of all fractions of sunflower and olive oil are shown in Figure-7. This figure indicates that the fraction $6-29$ of sunflower and the fraction 5-40 of olive contained FAME. The mixture of the fractions was applied to GC-FID to examine purity. The method was reported by Chakraborty et al. [24] to purify C20-22 n-3 polyunsaturated fatty acid esters from the oil of Sardinella longiceps.

The GC results show that the fractions of sunflower oil which is eluted by solvent $\mathrm{D}$, contain 95.8\% of linoleic acid, while the fractions of olive oil which is eluted by solvent C contain $97.9 \%$ of oleic acid. The fatty acid profiles of each fraction are shown in Table-8. The two fractions were used for preparing the further compounds.

Table 8-Fatty acid composition in oils after application of Argntation Chromatography

\begin{tabular}{|l|l|l|l|l|}
\hline \multirow{2}{*}{ Fatty acid } & Sunflower oil & Olive oil \\
\cline { 2 - 5 } & $\% \mathrm{FA}^{\mathrm{a}}$ & FA $^{\mathrm{bD}}$ & FA $^{\mathrm{a}}$ & $\% \mathrm{FA}^{\mathrm{bC}}$ \\
\hline Palmitic acid & 11.8 & 0.12 & 5.13 & 0.24 \\
\hline Linoleic acid & 80.99 & 95.8 & --- & --- \\
\hline Oleic acid & --- & --- & 89 & 97.93 \\
\hline Stearic acid & 5.03 & 3.55 & 2.8 & 0.15 \\
\hline $\begin{array}{l}\text { Cis-13-Eicosenoic } \\
\text { acid }\end{array}$ & 0.38 & --- & 1.3 & --- \\
\hline Other & 1.8 & & & 1.60 \\
\hline \%Yield & & 0.52 & 1.77 & 43.3 \\
\hline
\end{tabular}


a:Fatty acid composition before fractionation by $\mathrm{Ag}-\mathrm{Si}$ chromatography, b:Fatty acid composition after fractionation by $\mathrm{Ag}-\mathrm{Si}$ chromatography, $\mathrm{C}$ : eluted solvent is $1 \%$ acetone and $99 \%$ hexan, D: eluted solvent is $5 \%$ acetone and $95 \%$ hexan.

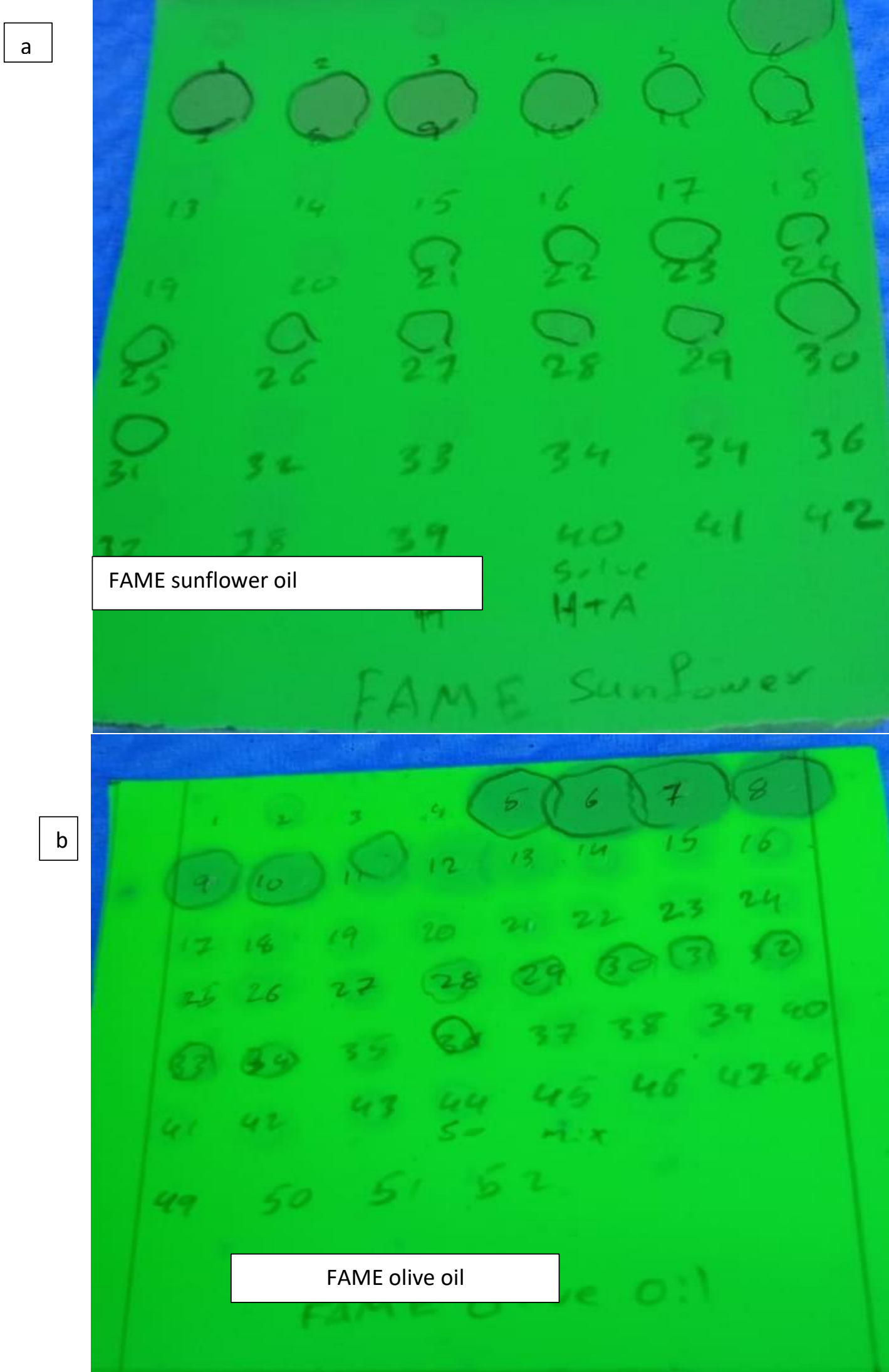

Figure 6-TLC of all fractions of a: sunflower oil FAME, and b: olive oil FAME 


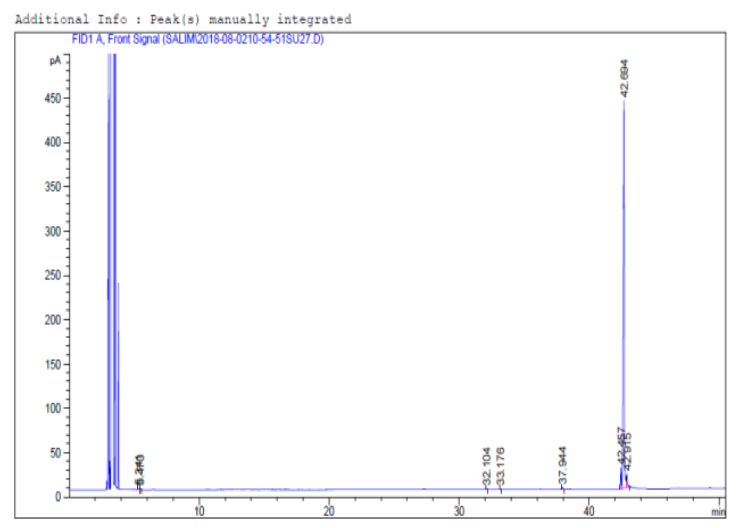

a

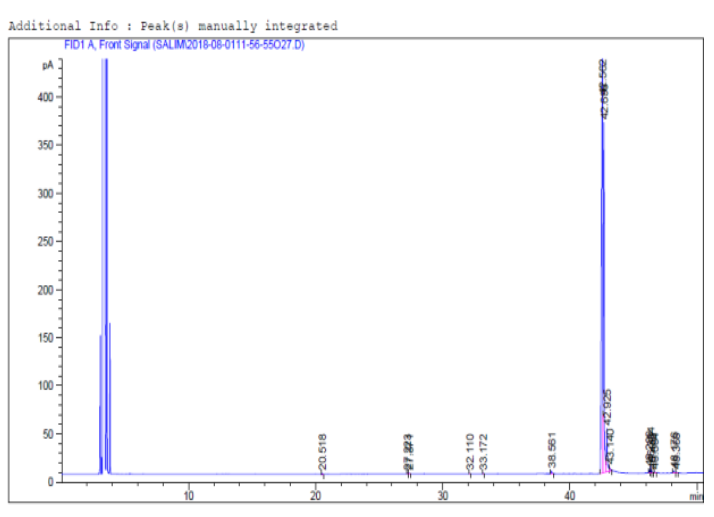

b

Figure 7- GC-FID chromatogram of a. sunflower FAME Fractions, b. olive FAME Fractions.

\section{Conclusions}

In conclusion, GC-MS and FT-IR are the suitable techniques to determine the fatty acids composition from oil. The results show that virgin coconut oil, olive, and sunflower oils are the main sources of saturated fatty acid SFAs, MUFAs, and PUFAs, respectively. Argentated Silica Gel Chromatography is a suitable method to separate fatty acid methyl ester, based on the degree of unsaturation. The present study suggests that ginger oil can be used as a source of saturated and unsaturated fatty acids.

\section{ACKNOWLEDGMENT}

The authors acknowledge the University of Salahaddin-Erbil to express their appreciation for supporting and sponsoring this project. The authors wish to thank the Department of Chemistry, Faculty of Science, University Technology Malaysia (UTM), for providing necessary facilities.

\section{APPENDIX}

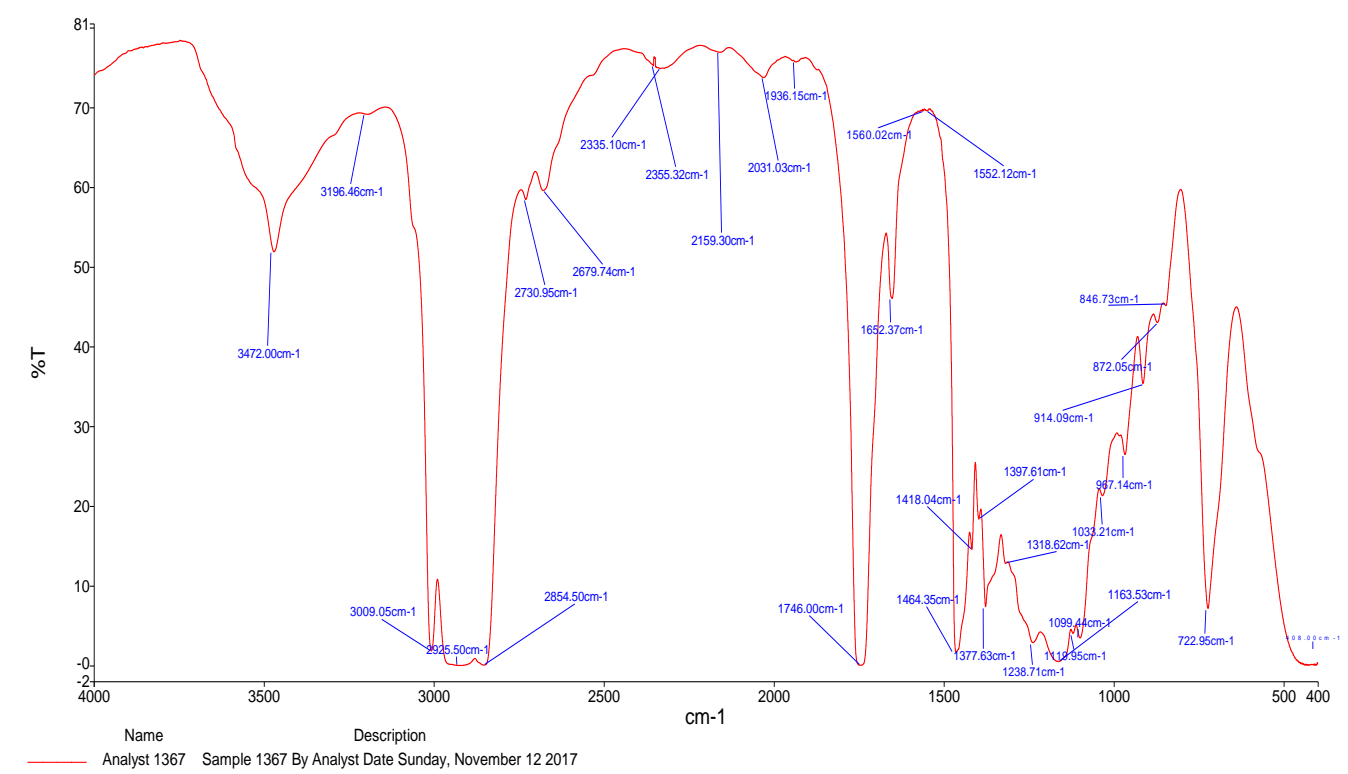

\section{FT-IR spectra of olive oil}




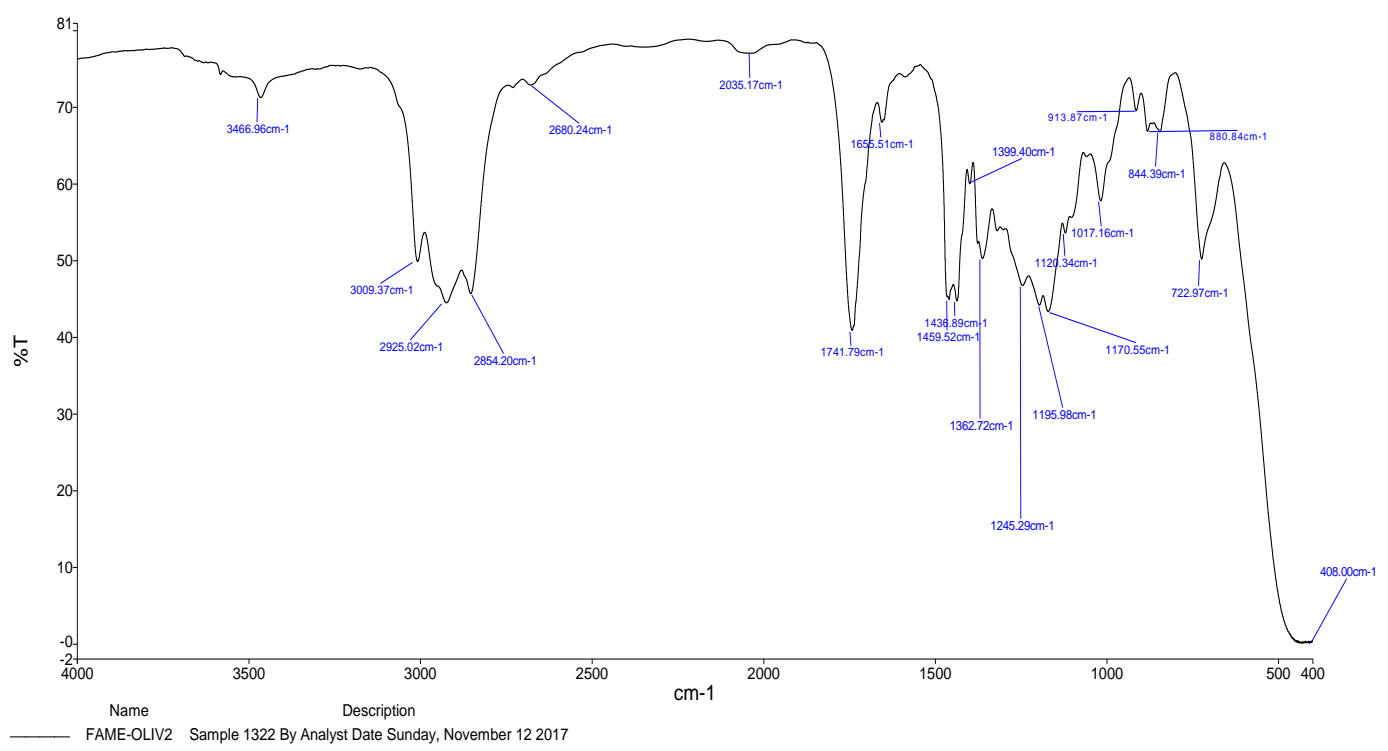

FT-IR spectra of FAME of olive Oil

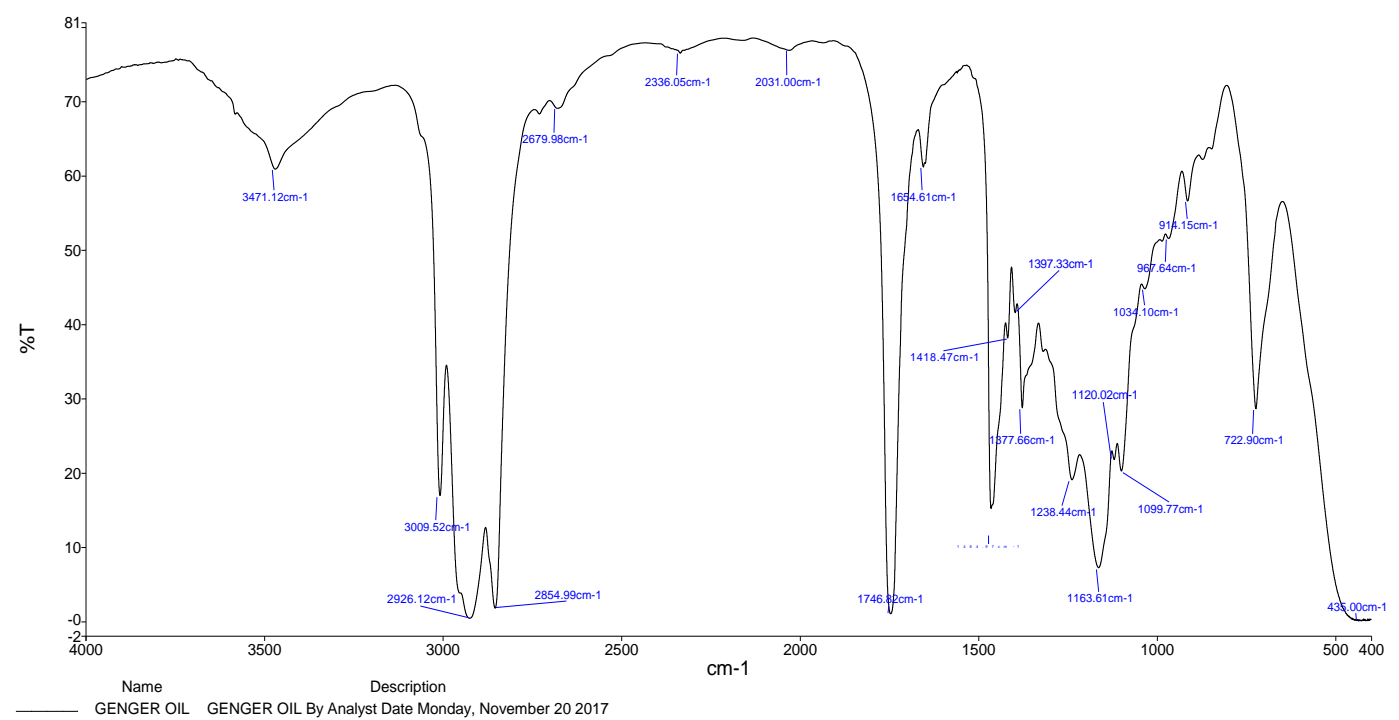

FT-IR spectra of ginger oil

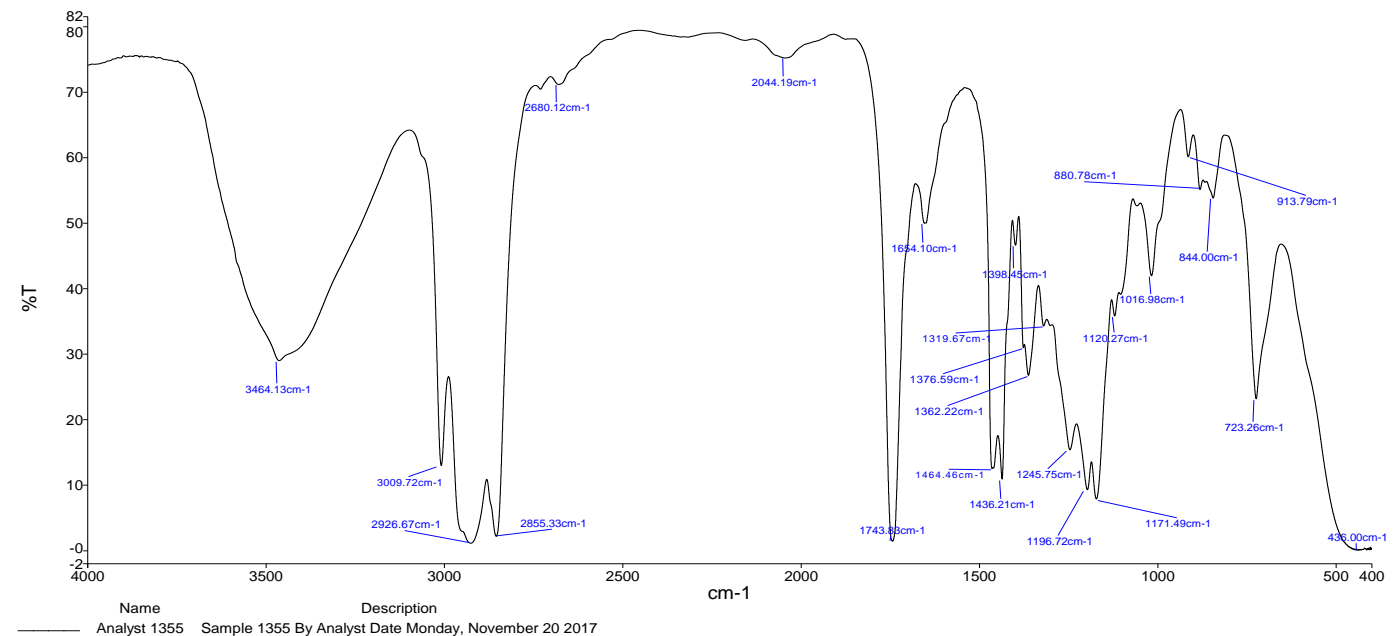

FT-IR spectra of FAME ginger oil 


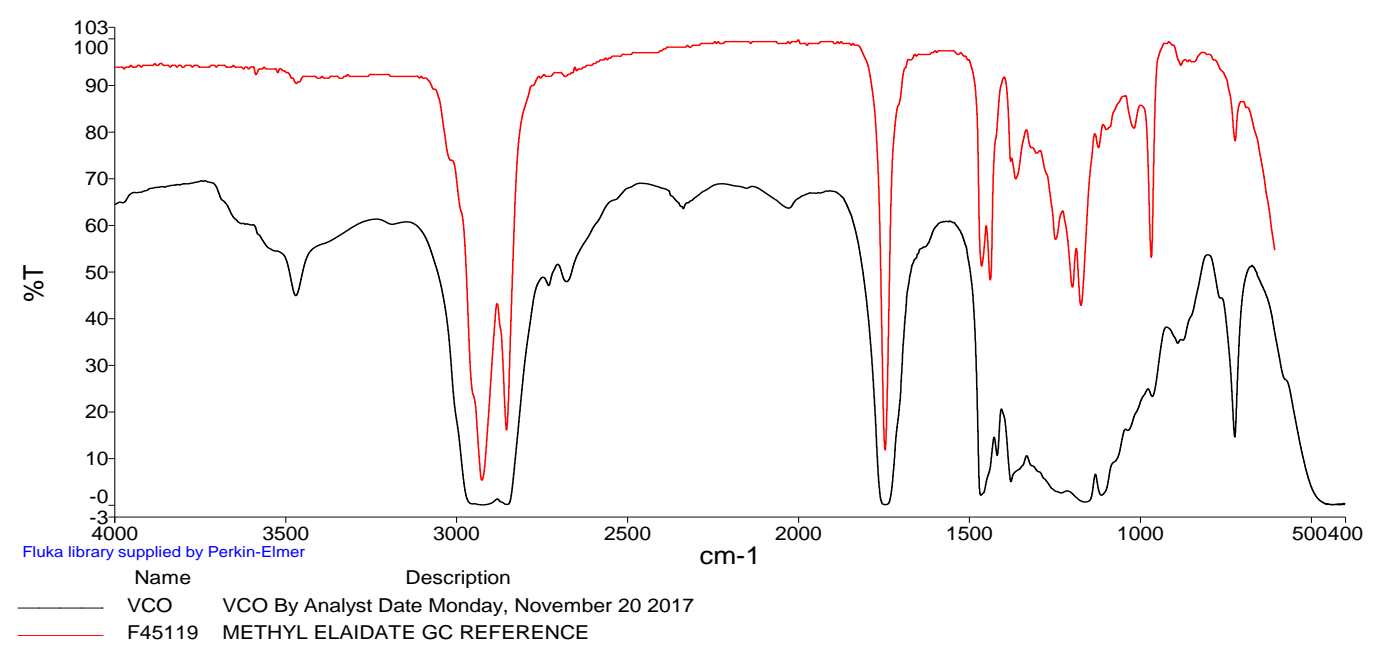

FT-IR spectra of virgin coconut oil

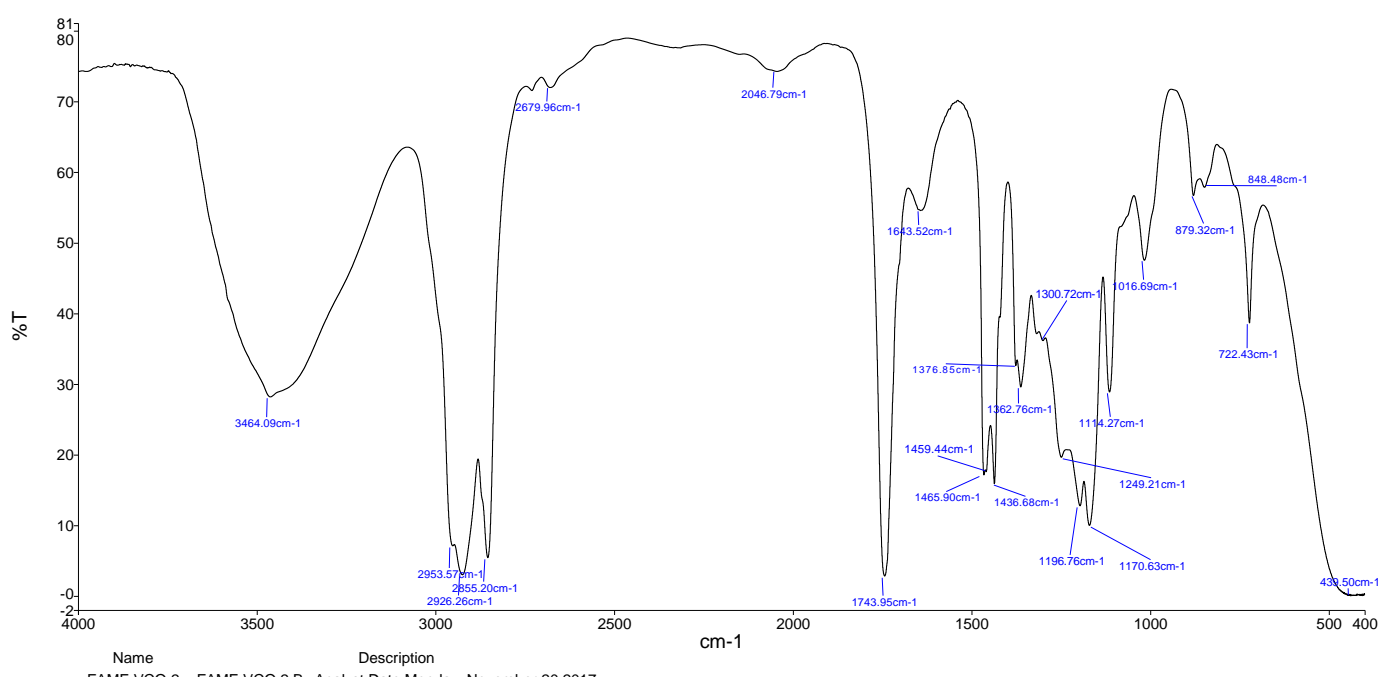

FT-IR spectra of FAME of virgin coconut oil 


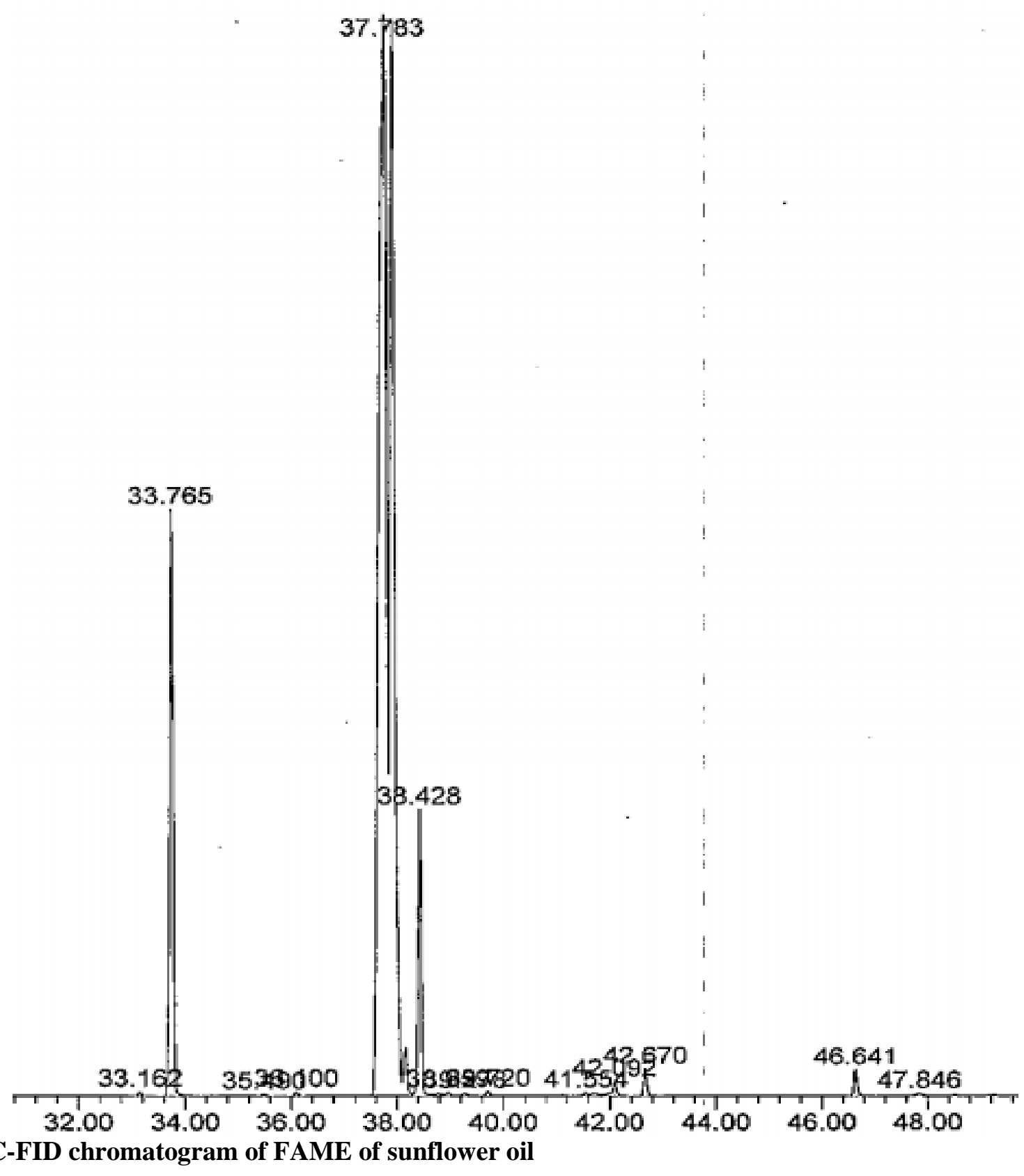




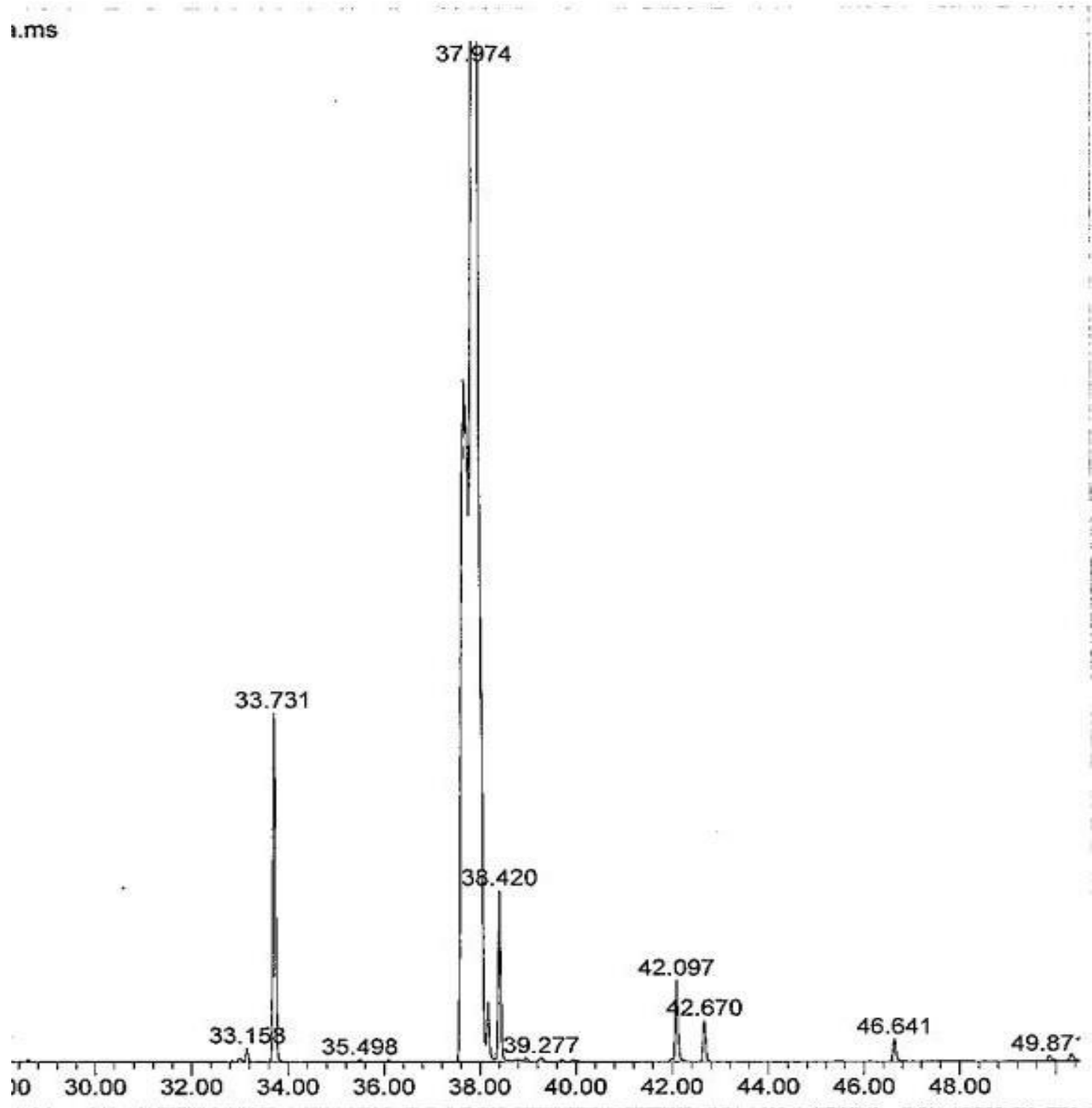

\section{GC-FID chromatogram of FAME of olive oil}

\section{References}

1. Díaz, $M$ et al.., 2006. Comparative study of ozonized olive oil and ozonized sunflower oil", Journal of the Brazilian Chemical Society, 17(2): 403-407. Available: 10.1590/s0103-5053200 60 00200026.

2. Gallardo-Velázquez M., Osorio-Revilla T., G., Castañeda-Pérez E. and Uribe-Hernández K. 2015. Characterization of Mexican Fishes According to Fatty Acid Profile and Fat Nutritional Indices", International Journal of Food Properties, 19(6): 1401-1412. Available: 10.1080/1094 2912. 2015. 1079787.

3. Hu F., 2002. Optimal Diets for Prevention of Coronary Heart Disease", JAMA, 288(20): 2569. Available: 10.1001/jama.288.20.2569.

4. Carvalho M., Mendonça M., Pinho D., Resck I. and Suarez P. 2012. Chromatographic analyses of fatty acid methyl esters by HPLC-UV and GC-FID", Journal of the Brazilian Chemical Society, 23(4): 763-769. Available: 10.1590/s0103-50532012000400023.

5. Cascant M., Breil C., Fabiano-Tixier A., Chemat, F. Garrigues S. and Guardia M. de la. 2018. Determination of fatty acids and lipid classes in salmon oil by near infrared spectroscopy", Food Chemistry, 239: 865-871. Available: 10.1016/j.foodchem.2017.06.158.

6. Golay P. and Dong.Y. 2015. Determination of Labeled Fatty Acids Content in Milk Products, Infant Formula, and Adult/Pediatric Nutritional Formula by Capillary Gas Chromatography: 
Single-Laboratory Validation, First Action 2012.13", Journal of AOAC INTERNATIONAL. 98(6): 1679-1696. Available: 10.5740/jaoacint.15-113.

7. Kaskoos R. 2011. "Fatty Acid Composition of Black Cumin Oil from Iraq. Research Journal of Medicinal Plant, 5(1): 85-89. Available: 10.3923/rjmp.2011.85.89.

8. Vingering N., Oseredczuk M., du Chaffaut L., Ireland J. and Ledoux M. 2010. Fatty acid composition of commercial vegetable oils from the French market analysed using a long highly polar column", Oléagineux, Corps gras, Lipides, 17(3): 185-192. Available: 10.1051/ocl. 2010. 0309.

9. J. Guil-Guerrero, P. Campra-Madrid and R. Navarro-Juárez. 2003. Isolation of some PUFA from edible oils by argentated silica gel chromatography", Grasas y Aceites, 54(2). Available: 10.3989/ gya. 2003.v54.i2.253.

10. Helrich, K. 1991"Official methods of analysis of the association of official analytical chemists", Analytica Chimica Acta,. 242: 302. Available: 10.1016/0003-2670(91)87088-o.

11. Zhao X. and Qiu X.. 2018. Analysis of the biosynthetic process of fatty acids in Thraustochytrium", Biochimie, vol. 144: 108-114. Available: 10.1016/j.biochi.2017.10.024.

12. Kamatou G. and Viljoen A. 2017. Comparison of fatty acid methyl esters of palm and palmist oils determined by GCxGC-ToF-MS and GC-MS/FID", South African Journal of Botany, 112: 483488. Available: 10.1016/j.sajb.2017.06.032.

13. Esfarjani1 F., Khoshtinat K., Zargaraan A., Mohammadi-Nasrabadi F., Salmani,Y. Saghafi Z., Hosseini H. and Bahmaei M.. 2019. "Evaluating the rancidity and quality of discarded oils in fast food restaurants" food science and nutrition journal. 7(7): 2302-2311. Available: doi: 10. 1002 /fsn3.1072

14. Sebastian, S. Ghazani and A. Marangoni. 2014. "Quality and safety of frying oils used in restaurants" Food Research International. 64: 420-423. Available: //doi.org/10.1016/j. foodres. 2014.07.033

15. Dooley F.. 1999. The named nurse in practice", Nursing Standard, 13(34): 33-38. Available: 10.7 748/ns1999.05.13.34.33.c2598.

16. Agnew M., Craigie C., Weralupitiya G., Reis M., Johnson P., and Reis M. 2019."Comprehensive Evaluation of Parameters Affecting One-Step Method for Quantitative Analysis of Fatty Acids in Meat" Metabolites. 9(189):1-15. Available: doi:10.3390/metabo9090189

17. Awadh M., Japir B., Salih N., Salimon J. 2016. Free Fatty Acids Separation From Malaysian High Free Fatty Acid Crude Palm Oil Using Molecular Distillation," Malaysian Journal of Analytical Science, 20(5): 1042-1051.

18. Strauss H. Li, H. and Snyder R. 2004. Differences in the IR Methylene Rocking Bands between the Crystalline Fatty Acids and n-Alkanes: Frequencies, Intensities, and Correlation Splitting", Journal of Physical Chemistry A, 8: 6629-6642.

19. Kotha, R. Natarajan S., Wang D. and Luthria D. 2019. "Compositional Analysis of Non-Polar and Polar Metabolites in 14 Soybeans Using Spectroscopy and Chromatography Tools" foods. 8: 557 570. Available: doi:10.3390/foods8110557

20. Ajayi I., Oderinde R., Kajogbola D. and Uponi J. 2006. Oil content and fatty acid composition of some underutilized legumes from Nigeria", Food Chemistry, 99(1): 115-120.

21. Poiana M. and Mincione A. 2004. Fatty acids evolution and composition of olive oils extracted from different olive cultivars grown in Calabrian area", Grasas y Aceites, 55(3): 282-290.

22. Basumatary S. and Deka D.. 2012. Identification of fatty acid methyl esters in biodiesel from Pithecellobiummonadelphum seed oil ", Der ChemicaSinica, 3(6): 1384-1393.

23. Sánchez A., Maceiras R., Cancela A. and Rodríguez M.. 2012. Influence of n-Hexane on in Situ Transesterification of Marine Macroalgae", Energies, 5(12): 243-257.

24. Chakraborty K., Joseph D. and Joseph D. 2016. Concentration and stabilization of C20-22 n-3 polyunsaturated fatty acid esters from the oil of Sardinella longiceps", Food Chemistry, 199: 828837. Available: 10.1016/j.foodchem.2015.12.082. 